\title{
Okadaic Acid, a Bioactive Fatty Acid from Halichondria okadai, Stimulates Lipolysis in Rat Adipocytes: The Pivotal Role of Perilipin Translocation
}

\author{
Nen-Chung Chang, ${ }^{1}$ Aming Chor-Ming Lin, ${ }^{2}$ \\ Cheng-Chen Hsu, ${ }^{3}$ Jung-Sheng Liu, ${ }^{4}$ Leo Tsui, ${ }^{4}$ Chien-Yuan Chen, ${ }^{4}$ \\ Thanasekaran Jayakumar, ${ }^{5}$ and Tsorng-Harn Fong ${ }^{3,4}$ \\ ${ }^{1}$ Division of Cardiovascular, Department of Internal Medicine, School of Medicine, College of Medicine, \\ Taipei Medical University Hospital, Taipei, Taiwan \\ ${ }^{2}$ Department of Emergency, Shin Kong Wu Ho-Su Memorial Hospital, Taipei 11101, Taiwan \\ ${ }^{3}$ Department of Anatomy, School of Medicine, College of Medicine, Taipei Medical University, No. 250, Wu-Hsing Street, \\ Taipei 11031, Taiwan \\ ${ }^{4}$ Graduate Institute of Medical Sciences, College of Medicine, Taipei Medical University, Taipei, Taiwan \\ ${ }^{5}$ Department of Pharmacology, School of Medicine, College of Medicine, Taipei Medical University, Taipei, Taiwan
}

Correspondence should be addressed to Tsorng-Harn Fong; thfong@tmu.edu.tw

Received 21 August 2013; Accepted 7 October 2013

Academic Editor: Joen-Rong Sheu

Copyright (C) 2013 Nen-Chung Chang et al. This is an open access article distributed under the Creative Commons Attribution License, which permits unrestricted use, distribution, and reproduction in any medium, provided the original work is properly cited.

\begin{abstract}
Lipid metabolism in visceral fat cells is correlated with metabolic syndrome and cardiovascular diseases. Okadaic-acid, a 38-carbon fatty acid isolated from the black sponge Halichondria okadai, can stimulate lipolysis by promoting the phosphorylation of several proteins in adipocytes. However, the mechanism of okadaic acid-induced lipolysis and the effects of okadaic acid on lipid-dropletassociated proteins (perilipins and beta-actin) remain unclear. We isolated adipocytes from rat epididymal fat pads and treated them with isoproterenol and/or okadaic acid to estimate lipolysis by measuring glycerol release. Incubating adipocytes with okadaic acid stimulated time-dependent lipolysis. Lipid-droplet-associated perilipins and beta-actin were analyzed by immunoblotting and immunofluorescence, and the association of perilipin A and B was found to be decreased in response to isoproterenol or okadaic acid treatment. Moreover, okadaic-acid treatment could enhance isoproterenol-mediated lipolysis, whereas treatment of several inhibitors such as KT-5720 (PKA inhibitor), calphostin C (PKC inhibitor), or KT-5823 (PKG inhibitor) did not attenuate okadaicacid-induced lipolysis. By contrast, vanadyl acetylacetonate (tyrosine phosphatase inhibitor) blocked okadaic-acid-dependent lipolysis. These results suggest that okadaic acid induces the phosphorylation and detachment of lipid-droplet-associated perilipin A and B from the lipid droplet surface and thereby leads to accelerated lipolysis.
\end{abstract}

\section{Introduction}

Adipose tissues play critical roles in energy storage, lipid metabolism, and glucose homeostasis. The development of obesity may be due to excess adipose tissues accumulation or abnormal lipid metabolism. Obesity increases the risk of cardiovascular diseases and diabetes mellitus type 2, comorbidities often detected in metabolic syndrome [1], and visceral fat is linked to metabolic disorders and increased risk of cardiovascular disease [2, 3]. Many hormones and drugs have been identified to participate in the regulation of lipid metabolism, and various hormones and drugs lead to lipolysis through distinct lipolytic pathways [4]. The most studied lipolytic pathway is the cAMP-dependent protein kinase A (PKA) pathway in adipocytes, in which catecholamines bind to beta-adrenoreceptors and activate membrane-bound adenylyl cyclases and thereby increase intracellular cAMP formation [5]. Subsequently, the elevated cAMP levels 
enhance PKA activity, leading to the phosphorylation and activation of hormone-sensitive lipase (HSL) [6] and lipiddroplet-associated perilipins [7]. Activated HSL and perilipins elicit the hydrolysis of triacylglycerol stored in lipid droplets and the release of free fatty acids and glycerol from adipocytes [8].

Okadaic acid, a polyether derivative of a 38-carbon fatty acid extracted from the black sponge Halichondria okadai, is a potent inhibitor of protein phosphatases-1 and -2A (PP1 and PP2A) [9, 10] and a known tumor promoter [11]. Okadaic acid has been used to study various cellular processes such as the cell cycle [12], apoptosis [13], nitric oxide metabolism [14], and calcium signaling [15]. Okadaic acid can stimulate protein phosphorylation rapidly and induce a variety of metabolic processes in diverse cell types [16, 17]. Treating adipocytes with okadaic acid markedly increases the phosphorylation of many proteins and stimulates basal lipolysis [16]. Okadaic acid has been reported to stimulate lipolysis by inducing the translocation of phosphorylated and activated HSL from the cytosol to the lipid-droplets to accelerate lipolysis [18].

In addition to catalytic lipases, perilipins, a family of proteins that coat the surface of lipid droplets $[7,19]$, have been proposed to regulate lipid metabolism in adipocytes $[8,20]$. Perilipin is produced as distinct isoforms that are generated through differential splicing. In adipocytes, perilipin $\mathrm{A}$ is the major isoform and perilipin $B$ is the less abundant and shorter variant. Both proteins arise from alternative splicing of mRNA transcripts and share a common N-terminal domain [21]. Phosphorylation of perilipin $\mathrm{A}$ is required for the translocation of HSL during PKA-stimulated lipolysis [22]. In adipocytes from perilipin-null animals, basal lipolysis level is higher and stimulated lipolysis is lower than in adipocytes from wild-type mice. These findings suggest that perilipins serve as gatekeeper proteins that are involved in regulating lipid storage and protecting lipids against the hydrolysis by lipases. Phosphorylated perilipins facilitate lipase function following lipolytic stimulation [20]. Okadaic acid treatment can promote perilipin phosphorylation in adipocytes [23], but the underlying molecular mechanism remains unclear. Previously, we showed that globular beta-actin was associated with intracellular lipid droplets in adipocytes [24] and examined how okadaic acid affected lipid-droplet-associated beta-actin.

The clinical implications of okadaic acid have been well documented as okadaic acid administered orally to rats causes intestinal damage, diarrhea, and death but has no detectable effect on the liver [25]. On the other hand, it has been reported that intravenous administration of okadaic acid causes little effect on the intestinal function but severely affects the liver [26]. Apart from these acute effects, the okadaic acid group of toxins seems to have some important chronic effects. These toxins have been found to be potent tumor promoters [27], and the possibility that they are also tumor inducers has been suggested [28]. Although existing observations of human populations are not conclusive, there are epidemiologic lines of evidence that associate these toxins with digestive cancer [29].
In this study, we used okadaic acid to induce lipolysis in primary cultures of isolated rat adipocytes. We report that glycerol release was increased in a time-dependent manner after incubation of cells with okadaic acid. We also analyzed lipid-droplet-associated perilipin A/B and beta-actin by immunoblotting and immunofluorescent labeling and found that treatment with okadaic acid induced the detachment of perilipin A and B but not of beta-actin from the surface of lipid droplets. Furthermore, using specific inhibitors of protein kinase A (KT-5720), protein kinase G (KT-5823), protein kinase $\mathrm{C}$ (calphostin $\mathrm{C}$ ), or tyrosine phosphatases (vanadyl acetylacetonate), we examined the signaling pathways through which okadaic acid induces lipolysis in primary rat adipocytes.

\section{Materials and Methods}

2.1. Reagents. Okadaic acid ( $\geq 90 \%)$, isoproterenol, collagenase (type II), poly-L-lysine, leupeptin, benzamidine, sodium fluoride $(\mathrm{NaF})$, ethylenediaminetetraacetic acid (EDTA), beta-mercaptoethanol, Triton X-100, Tween-20, dimethyl sulfoxide (DMSO), Free Glycerol Determination Kit, diaminobenzidine (DAB), n-propyl gallate, KT-5720, KT5823, calphostin $\mathrm{C}$, vanadyl acetylacetonate, bovine serum albumin (BSA), tris[hydroxymethyl] aminomethane (Tris), $\mathrm{N}$-tris[hydroxymethyl]methyl-2-aminoethanesulfonic acid (TES), 3-(4,5-dimethylthiazol-2-yl)-2,5-diphenyltetrazolium bromide (MTT), glutaraldehyde, rabbit polyclonal antiperilipin A/B antibodies, mouse monoclonal anti-beta-actin antibody, and FITC-conjugated anti-rabbit IgG were all purchased from Sigma-Aldrich (St. Louis, MO). Biotinconjugated anti-rabbit IgG and biotin-conjugated anti-mouse IgG that was preabsorbed with rat serum were purchased from Vector Labs (Burlingame, CA). Streptavidin conjugated with peroxidase was purchased from DAKO (Copenhagen, Denmark). DMEM/F12 medium (phenol-red-free) was purchased from GIBCO (Grand Island, NY), and materials required for sodium dodecyl sulfate-polyacrylamide gel electrophoresis (SDS-PAGE) were purchased from Bio-Rad (Hercules, CA).

2.2. Animals. Adult male Wistar rats with body weights in the 200-300 g range were used for the experiments. Rats were housed under a 12:12 h light/dark daily cycle at $23^{\circ} \mathrm{C}$ and were provided with standard laboratory rat chow and water. All animal care was approved under guidelines established by the Taipei Medical University Ethical Committee for Laboratory Animals.

2.3. Preparation and Incubation of Isolated Adipocytes. Rats were injected intraperitoneally with sodium pentobarbital ( $40 \mathrm{mg} / \mathrm{kg}$ body weight) and adipocytes were isolated from the sacrificed rats using procedures described by Rodbell [30] with minor modifications. Briefly, epididymal fat pads were removed immediately after sacrificing animals and were washed and incubated in DMEM/F12 medium (phenol-redfree). The fat pads were minced with scissors and placed in glass vials with medium, and the fat tissue was digested using a collagenase solution $(3.3 \mathrm{mg} / \mathrm{mL}$ of type-II collagenase in 
DMEM/F12 medium, $\mathrm{pH} 7.4$, with $3 \mu \mathrm{M}$ glucose, $4 \%$ BSA) with constant shaking at $75 \mathrm{rpm}$ for $30 \mathrm{~min}$ at $37^{\circ} \mathrm{C}$. Subsequently, fat cells were filtered through a nylon mesh and centrifuged for $5 \mathrm{~min}$ at $1000 \mathrm{rpm}$, after which the supernatant layer of cells was washed thrice with medium to eliminate collagenase. The packed fat cells were resuspended in buffer A (25 mM TES, pH 7.4, $135 \mathrm{mM} \mathrm{NaCl}, 5 \mathrm{mM} \mathrm{KCl}$, and $1 \mathrm{mM}$ $\left.\mathrm{MgCl}_{2}\right)$ at $37^{\circ} \mathrm{C}$ and adjusted to a density of $1 \times 10^{5}$ cells $/ \mathrm{mL}$.

2.4. Drug Treatment. Adipocytes were incubated in a total volume of $500 \mu \mathrm{L}$ in the presence or absence of various reagents (as shown in the figures); $450 \mu \mathrm{L}$ of fat cells was supplemented with BSA $(2.5 \%, \mathrm{w} / \mathrm{v})$ and incubated with $50 \mu \mathrm{L}$ of the drug solution (okadaic acid or isoproterenol) for the indicated periods at $37^{\circ} \mathrm{C}$ in a $\mathrm{CO}_{2}$ incubator. The final concentrations of okadaic acid and isoproterenol were $1 \mu \mathrm{M}$ and $10 \mu \mathrm{M}$, respectively. After incubation, the reaction mixture was mixed well and then centrifuged at $1000 \mathrm{rpm}$ for 5 min to separate the medium and the fat cells, which were used to assay for glycerol release and to isolate intracellular lipid droplets, respectively.

2.5. Measurement of Lipolysis Based on Glycerol Release. Lipolysis was measured by determining the amount of glycerol released into the medium that was collected after drug treatment and centrifugation; glycerol release was measured using a Free Glycerol Determination Kit. The glycerol content was calculated from absorbance at $540 \mathrm{~nm}$ according to the manufacturer's instructions, and glycerol release was expressed as a percentage of the vehicle control ( $0.1 \%$ DMSO).

2.6. Isolation of Intracellular Lipid Droplets and SDS-PAGE. Intracellular lipid droplets were isolated from fat cells according to the method of Okuda et al. [31] with minor modification. Briefly, isolated fat cells were washed thrice with normal saline to remove BSA from the reaction medium and then incubated in lysis buffer ( $5 \mathrm{mM}$ Tris buffer, $\mathrm{pH}$ 7.4, 0.025\% Triton X-100, $1 \mathrm{mM}$ EDTA, $50 \mathrm{mM} \mathrm{NaF}, 10 \mu \mathrm{g} / \mathrm{mL}$ leupeptin, and $1 \mathrm{mM}$ benzamidine) on ice for $15 \mathrm{~min}$. The samples were vortexed and then centrifuged at $13000 \times \mathrm{g}$ for $15 \mathrm{~min}$ at $4^{\circ} \mathrm{C}$. The floating fat-cake fractions were collected and mixed with equal volumes of $2 \mathrm{X}$ sample buffer $(62.5 \mathrm{mM}$ Tris, $\mathrm{pH}$ $6.8,5 \%$ beta-mercaptoethanol, $2 \%$ SDS, and $10 \%$ glycerol). The samples were heated to $95^{\circ} \mathrm{C}$ for $5 \mathrm{~min}$ and clarified by centrifugation at $10000 \mathrm{rpm}$ for $5 \mathrm{~min}$ before using them for SDS-PAGE. Equal amounts of fat-cake extracts were loaded and resolved by SDS-PAGE on 7.5\% polyacrylamide slab gels.

2.7. Western Blotting. After electrophoresis, proteins were transferred to nitrocellulose membranes and blocked with $5 \%$ nonfat milk in Tris-buffered saline (TBS; $50 \mathrm{mM}$ Tris and $200 \mathrm{mM} \mathrm{NaCl}, \mathrm{pH} 7.5$ ), containing $0.05 \%$ Tween-20 at room temperature for $1 \mathrm{~h}$ and then incubated overnight at $4^{\circ} \mathrm{C}$ with rabbit polyclonal anti-perilipin $\mathrm{A} / \mathrm{B}$ antibodies or mouse monoclonal anti-beta-actin antibody diluted in TBS. After washing with TBS, the membrane strips were incubated with biotin-conjugated anti-rabbit IgG or biotin-conjugated anti-mouse IgG (rat serum preabsorbed to avoid nonspecific binding between mouse and rat) at room temperature for
$1 \mathrm{~h}$, washed with TBS, and then incubated with peroxidaseconjugated streptavidin at room temperature for $1 \mathrm{~h}$ to enhance the signals of immunoreactive bands. After washing again with TBS, immunoreactive bands were visualized by exposing membranes to a diaminobenzidine solution (5\% diaminobenzidine and $0.02 \% \mathrm{H}_{2} \mathrm{O}_{2}$ in TBS).

\subsection{Immunofluorescent Labeling of Isolated Intracellular Lipid} Droplets. Isolated intracellular lipid droplets were placed on $10 \%$ poly-L-lysine-coated slides for $20 \mathrm{~min}$ at room temperature for adhesion. After washing with phosphate-buffered saline (PBS: $137 \mathrm{mM} \mathrm{NaCl}, 2.7 \mathrm{mM} \mathrm{KCl}, 1.5 \mathrm{mM} \mathrm{KH} \mathrm{PO}_{4}$, and $8 \mathrm{mM} \mathrm{Na}_{2} \mathrm{HPO}_{4}, \mathrm{pH} 7.4$ ), the isolated lipid droplets were fixed using $2 \%$ glutaraldehyde in PBS for $5 \mathrm{~min}$. After washing with PBS, the lipid droplets were incubated with $5 \%$ nonfat milk in PBS for $30 \mathrm{~min}$ at room temperature to block nonspecific binding sites. The samples were next incubated with rabbit polyclonal anti-perilipin $\mathrm{A} / \mathrm{B}$ antibodies at $4^{\circ} \mathrm{C}$ overnight. After washing with PBS, the samples were incubated with FITC-conjugated anti-rabbit IgG for $1 \mathrm{~h}$ at room temperature. After washing again with PBS, the samples were mounted with $2 \%$ n-propyl gallate and $60 \%$ glycerol in PBS $(\mathrm{pH} 8.0)$, sealed in place using nail polish, and examined using a Nikon epifluorescence microscope (Nikon, Tokyo, Japan).

2.9. Statistical Analysis. Data are presented as the mean \pm $\mathrm{SE}$ from at least 3 independent experiments. The significance of differences between experimental and control groups was assessed using Student's $t$-test $P<0.05$ was considered statistically significant.

\section{Results}

3.1. Okadaic Acid Induces Lipolysis in a Time-Dependent Manner. We investigated the effect of okadaic acid on lipolysis in rat visceral fat cells. Okadaic acid $(1 \mu \mathrm{M})$ increased glycerol release by cultured adipocytes in a time-dependent manner (Figure 1(a)): the amounts of glycerol released were $15.5 \pm$ $0.2,21.6 \pm 0.8,29.5 \pm 0.2,47.9 \pm 0.1$, and $74.9 \pm 2.3 \mu \mathrm{g} / \mathrm{mL}$ of packed cells following treatment with okadaic acid for 0 , $15,30,60$, and $120 \mathrm{~min}$, respectively. During incubation for $15,30,60$, and $120 \mathrm{~min}$, lipolysis increased 1.4-, 1.9-, 3.1-, and 4.8-fold, respectively (Figure 1(b)).

3.2. Okadaic Acid Treatment Diminishes the Association of Perilipins A and B with Lipid Droplets. To explore the role of lipid-droplet-associated perilipins in okadaic-acid-induced lipolysis, we used immunoblotting to examine perilipins during the 120 min treatment with okadaic acid. Almost no lipid-droplet-associated perilipin A was detected after cells were treated for $30 \mathrm{~min}$ with okadaic acid (data not shown), and, therefore, we tested shorter incubation times. To investigate the short-term effects of okadaic acid on lipolysis, fat cells were treated with $1 \mu \mathrm{M}$ okadaic acid for $0,5,10,15,20$, and $30 \mathrm{~min}$. Glycerol release increased only slightly after incubation with okadaic acid for $5 \mathrm{~min}$ but increased substantially after incubation for 10, 15, 20, and 30 min (Figure 2(a)). Furthermore, we used immunoblotting 


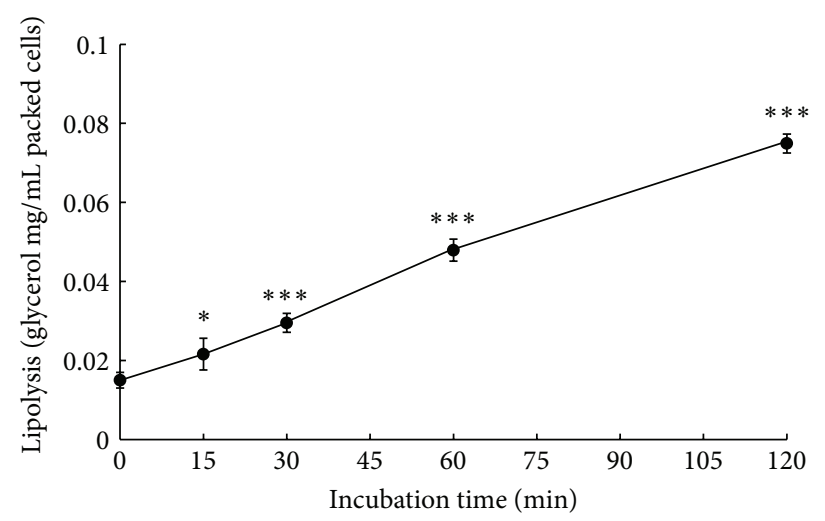

(a)

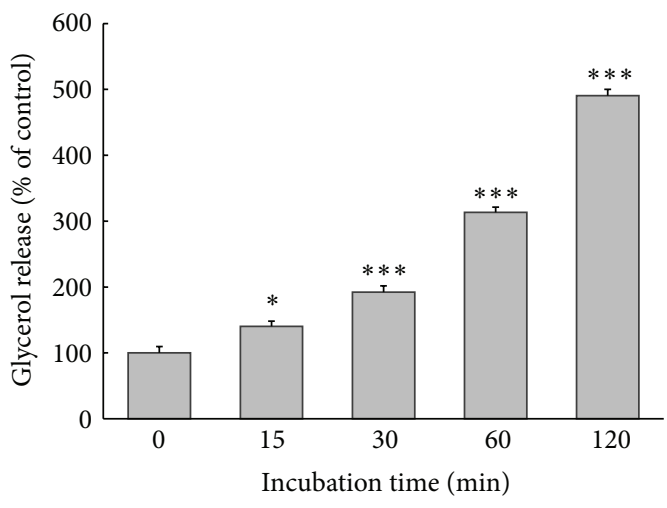

(b)

FIGURE 1: Time course of okadaic-acid-induced glycerol release in rat adipocytes. Fat cells were incubated with okadaic acid $\left(1 \mu \mathrm{M}, 37^{\circ} \mathrm{C}\right)$ for the indicated periods. After incubation, media were collected and glycerol release was measured as described in Materials and Methods. Glycerol released into the media was assayed as an index of lipolysis and expressed as $\mathrm{mg} / \mathrm{mL}$ of packed cell volume (a). Glycerol release data are expressed as percentages of the values obtained after incubation for $0 \mathrm{~min}(\mathrm{~b})$. Each point represents the mean $\pm \mathrm{SE}$ of three separate experiments. ${ }^{*} P<0.05$ and ${ }^{* * *} P<0.001$ compared with values of 0 min incubation.

to examine lipid-droplet-associated perilipins during the 30 min incubation with okadaic acid. The rabbit polyclonal anti-perilipin $\mathrm{A} / \mathrm{B}$ antibodies can label native perilipin $\mathrm{A}$ $(62 \mathrm{kD})$, phosphorylated perilipin $\mathrm{A}(65 \mathrm{kD})$, and perilipin $\mathrm{B}$ (46 and $48 \mathrm{kD})$. We detected phosphorylated perilipin A $(65 \mathrm{kD})$ after $5 \mathrm{~min}$ treatment with okadaic acid and observed that the levels of lipid-droplet-associated perilipin A $(62 \mathrm{kD}$ and $65 \mathrm{kD})$ and perilipin $\mathrm{B}(46 \mathrm{kD}$ and $48 \mathrm{kD})$ decreased gradually following okadaic acid treatment (Figure 2(b)). Quantification of these results demonstrated that total perilipin A decreased only by 0.98 -fold after $5 \mathrm{~min}$ but decreased significantly after $10,15,20$, and $30 \mathrm{~min}$ incubation by $0.56-$, $0.47-, 0.22-$, and 0.18 -fold, respectively (Figure $2(\mathrm{c})$ ). The levels of total perilipin B decreased significantly after 5, 10, 15,20 , and $30 \mathrm{~min}$ incubation by $0.73-, 0.65-, 0.51-, 0.26-$, and 0.35 -fold, respectively (Figure $2(\mathrm{~d})$ ). By contrast, the level of lipid-droplet-associated beta-actin $(42 \mathrm{kD})$ did not decrease noticeably during the $30 \mathrm{~min}$ incubation with okadaic acid (Figure 2(b)).

\subsection{Okadaic Acid and Isoproterenol Induce Detachment of} Perilipins from Lipid Droplets. We used immunofluorescent labeling to investigate morphologically how isoproterenol and okadaic acid affect lipid-droplet-associated perilipins. Labeling with the polyclonal anti-perilipin antibodies revealed bright fluorescence along the circumference of the isolated intracellular lipid droplets in the buffer-A group (Figures 3(a) and 3(b)) and in the 0.1\%-DMSO group (Figures 3(c) and $3(\mathrm{~d}))$. This result indicated that perilipins are not only coisolated with intracellular lipid droplets but also associated with the surface of lipid droplets.

When we incubated fat cells with isoproterenol $(10 \mu \mathrm{M})$ or okadaic acid $(1 \mu \mathrm{M})$ for $120 \mathrm{~min}$ and then isolated intracellular lipid droplets for immunofluorescent labeling, only weak fluorescence was detected surrounding the lipid droplets in the isoproterenol-treated group (Figures 3(e) and 3(f)) and okadaic-acid-treated group (Figures 3(g) and 3(h)). This result suggested that most of the perilipins detached from the surface of lipid droplets after cells were incubated with the drugs.

3.4. Okadaic Acid Enhances Isoproterenol-Induced Lipolysis. Isoproterenol $(10 \mu \mathrm{M})$ or okadaic acid $(1 \mu \mathrm{M})$ has been shown previously to induce lipolysis [16]. To compare the signal transduction pathways in the lipolysis induced by okadaic acid and isoproterenol, we combined the 2 drugs and stimulated fat cells. Incubation of cells with isoproterenol $(10 \mu \mathrm{M})$ for $120 \mathrm{~min}$ stimulated glycerol release that was 3.0fold higher than in the buffer-A group, and incubation with okadaic acid $(1 \mu \mathrm{M})$ for $120 \mathrm{~min}$ stimulated glycerol release that was 4.1-fold higher than in the DMSO group; however, incubation of cells with both isoproterenol and okadaic acid for $120 \mathrm{~min}$ stimulated 5.6-fold higher glycerol release compared to the DMSO group (Figure 4). These results demonstrated that okadaic acid treatment can enhance isoproterenol-induced lipolysis in rat adipocytes.

\subsection{A Tyrosine-Phosphatase Inhibitor but Not Inhibitors} of PKA, PKC, and PKG Regulates Okadaic-Acid-Induced Lipolysis. To determine whether PKA, PKG, and PKC affect okadaic-acid-induced lipolysis in adipocytes, we used KT5720 (specific inhibitor of PKA), KT-5823 (specific inhibitor of $\mathrm{PKG}$ ), and calphostin C (specific inhibitor of PKC). Basal level of glycerol release was not affected by treatment with these 3 inhibitors, and preincubating cells with the inhibitors did not abolish or attenuate okadaic-acid-induced lipolysis (Figure 5). By contrast, preincubation with the tyrosinephosphatase blocker vanadyl acetylacetonate $(300 \mu \mathrm{M})$ potently inhibited okadaic-acid-induced lipolysis (Figure 6). The data suggested that tyrosine phosphatases, but not PKA, $\mathrm{PKG}$, or PKC, are involved in okadaic-acid-induced lipolysis in rat visceral fat cells. 


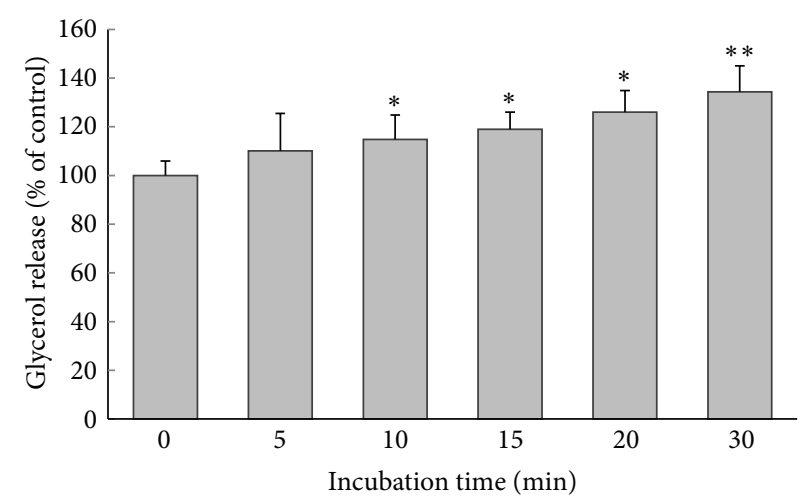

(a)

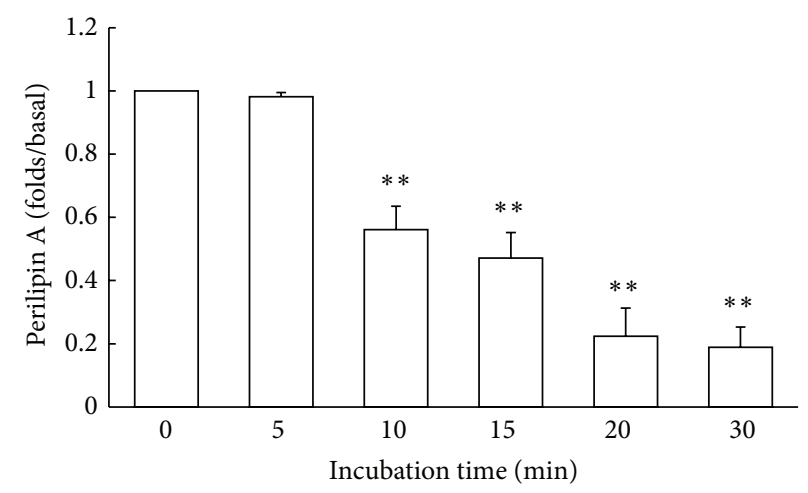

(c)

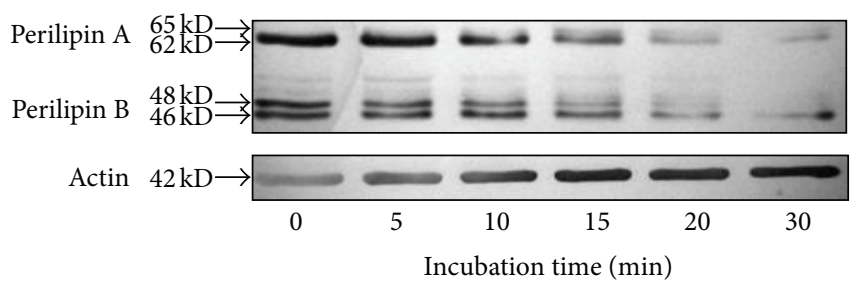

(b)

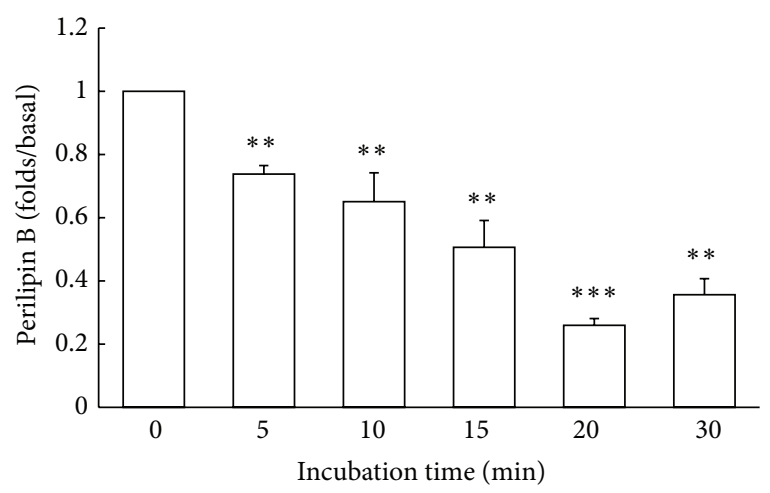

(d)

FIGURE 2: Effects of okadaic acid on lipid-droplet-associated perilipin A and B in rat adipocytes. Cells were incubated with okadaic acid (1 $\mu \mathrm{M}$, $37^{\circ} \mathrm{C}$ ) for the indicated periods. After incubation, each reaction mixture was centrifuged to separate the medium from the fat cells. Glycerol release was measured as described in Materials and Methods, and glycerol release data are expressed as percentages of the values obtained after incubation for $0 \mathrm{~min}$ (a). After incubation, fat cells were homogenized and centrifuged and the proteins of the fat cake fraction were separated using SDS-PAGE (7.5\% gels) and subjected to immunoblotting with a primary antibody against perilipins. Immunoblots showing perilipin $\mathrm{A}(62 \mathrm{kD}$ and $65 \mathrm{kD})$ and $\mathrm{B}(46 \mathrm{kD}$ and $48 \mathrm{kD})$ or beta-actin $(42 \mathrm{kD})$ from okadaic-acid-treated cells (b). Immunoreactive perilipin A (c) and perilipin B (d) were quantified as a percentage relative to the density in unstimulated fat cells. Each point represents the mean \pm SE of three separate experiments; ${ }^{*} P<0.05,{ }^{* *} P<0.01$, and ${ }^{* * *} P<0.001$ compared with values of 0 min incubation. The shift in the molecular weight of perilipin A from $62 \mathrm{kD}$ to $65 \mathrm{kD}$ could be observed after 5 min stimulation with okadaic acid.

\section{Discussion}

Our results have demonstrated that treatment of adipocytes with okadaic acid can induce lipolysis in a time-dependent manner. Perilipin A $(62 \mathrm{kD})$ and $\mathrm{B}(46$ and $48 \mathrm{kD})$ and betaactin $(42 \mathrm{kD})$ were abundant in quiescent fat cells and were associated with lipid droplets isolated from these cells. After incubating adipocytes for $5 \mathrm{~min}$ with okadaic acid, phosphorylated perilipin A $(65 \mathrm{kD})$ was detected, and following okadaic acid treatment for $10 \mathrm{~min}$, the amounts of perilipin $\mathrm{A}$ and $\mathrm{B}$ associated with lipid droplets decreased and glycerol release increased substantially. Furthermore, okadaicacid-induced lipolysis was suppressed by an inhibitor of tyrosine phosphatases but not by inhibitors of PKA, PKG, or PKC. These results suggest that treatment with okadaic acid activates tyrosine phosphatases and leads to perilipin A phosphorylation, which results in the detachment of perilipin $A$ and $B$ from the surface of lipid droplets and leads to lipolysis and glycerol release in rat visceral adipocytes.

Okadaic acid, a polyether derivative of fatty acid, can penetrate the plasma membrane readily and inhibit PP1 and PP2A potently $[16,17]$. When adipocytes are incubated with $1 \mu \mathrm{M}$ okadaic acid, which is sufficient for inhibiting PP1 and PP2A, the phosphorylation of many proteins is increased and glycerol release is stimulated in adipocytes $[16,23]$. PP1 and PP2A are abundant in rat adipocytes and also the major phosphatases in these cells [32]. PP2A is the principal phosphatase responsible for dephosphorylating HSL in adipocytes [33]. Conversely, PP1 is the main phosphatase that dephosphorylates perilipin in adipocytes [34]. Thus, treatment with okadaic acid could inhibit both PP1 and PP2A to enhance the phosphorylation of both perilipin and HSL and stimulate lipolysis. In our study, treatment with okadaic acid $(1 \mu \mathrm{M}$, for $2 \mathrm{~h})$ increased the release of glycerol 4.8 -fold in freshly prepared fat cell suspensions (1 $\times 10^{5}$ cells $/ \mathrm{mL}$ ). Previously, glycerol release was increased by approximately 11-fold in freshly prepared fat cell suspensions $\left(3 \times 10^{5}\right.$ cells $\left./ \mathrm{mL}\right)$ incubated with $2 \mu \mathrm{M}$ of okadaic acid for $3 \mathrm{~h}$ [35]. Thus, okadaic acid might induce lipolysis in a concentration- and time-dependent manner.

Lipid-droplet-associated perilipin is considered to act as a barrier or gatekeeper with critical roles in regulating cellular 


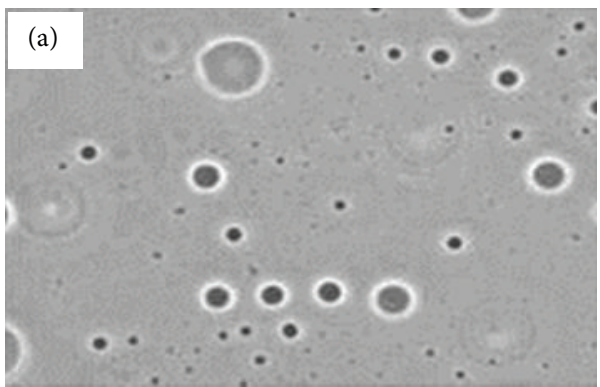

(a)

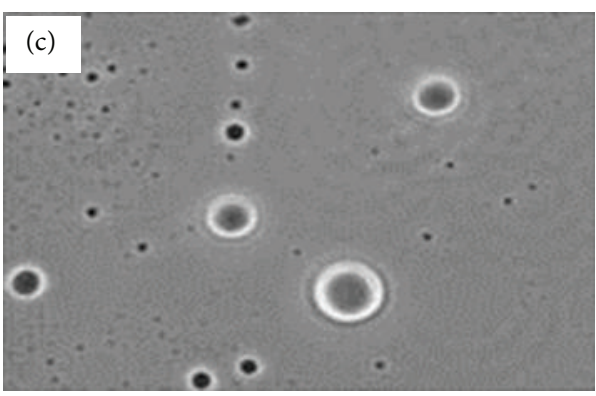

(c)

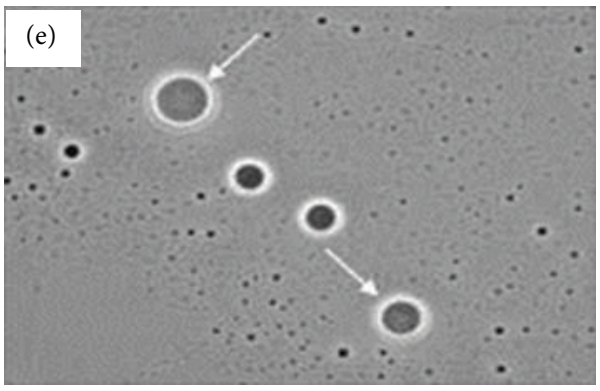

(e)

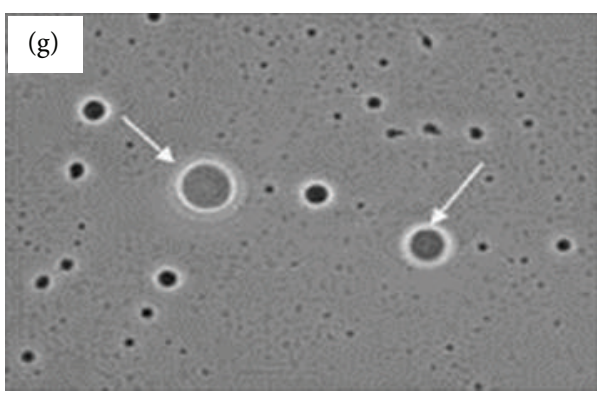

(g)

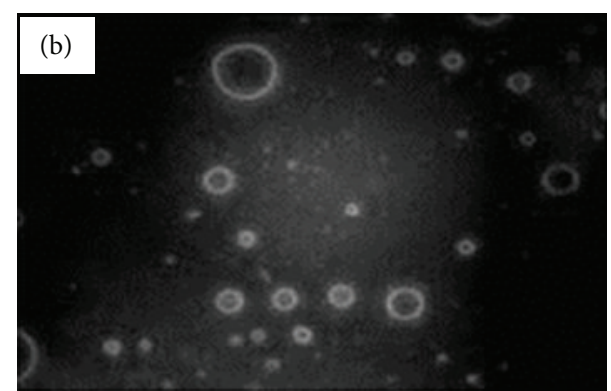

(b)

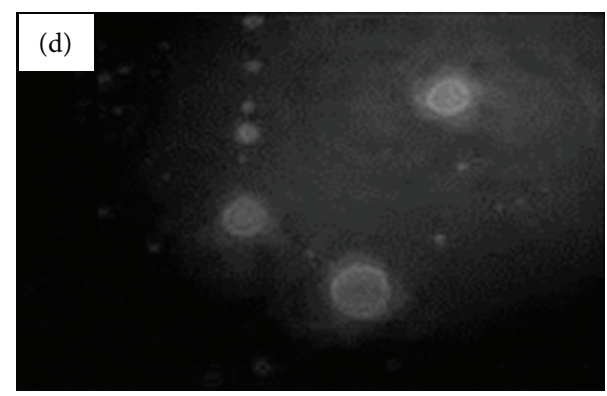

(d)

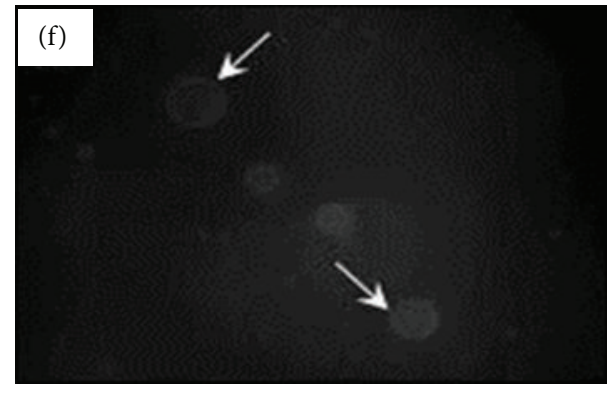

(f)

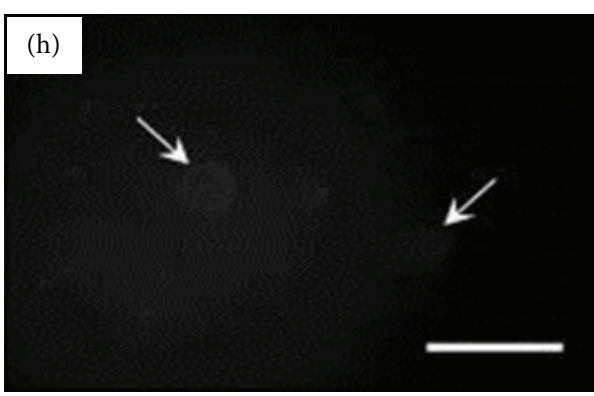

(h)

FIGURE 3: Immunofluorescent labeling of perilipin A/B in isolated intracellular lipid droplets. Adipocytes were incubated with buffer A, DMSO, isoproterenol $(10 \mu \mathrm{M})$, or okadaic acid $(1 \mu \mathrm{M})$ for $2 \mathrm{~h}$ at $37^{\circ} \mathrm{C}$. Perilipins were assembled as a bright ring surrounding the surface of lipid droplets in buffer A control ( $\mathrm{a}$ and b) and DMSO ( $\mathrm{c}$ and d), but labeling for perilipins was weak on lipid droplets in the isoproterenolstimulated group (e and $\mathrm{f}$ ) and absent on lipid droplets in the okadaic-acid-stimulated group ( $\mathrm{g}$ and $\mathrm{h}$ ). Figures (a), (c), (e), and (g) show phase-contrast images of figures (b), (d), (f), and (h), respectively. Arrows indicate isolated intracellular lipid droplets. Bar $=20 \mu \mathrm{m}$.

lipid metabolism $[8,20]$. Perilipin $\mathrm{A}(62 \mathrm{kD})$ is a prominent phosphoprotein that becomes phosphorylated after isoproterenol treatment, after which the protein migrates as a $65 / 67 \mathrm{kD}$ doublet in SDS-PAGE and is also the most heavily radiolabeled protein in the cell [7]. The anti-perilipin A/B polyclonal antibodies we used in this study can recognize native perilipin $A(62 \mathrm{kD})$, phosphorylated perilipin $A$
$(65 \mathrm{kD})$, and two perilipin $\mathrm{B}$ bands (46 and $48 \mathrm{kD}$ ) on immunoblots. The $65 / 67 \mathrm{kD}$ doublet of phosphorylated perilipin A was not identified here possibly because we did not use radiolabels or because of the limitations of the antiperilipin antibody.

Treatment with isoproterenol can stimulate the phosphorylation and translocation of perilipin from the lipid-droplet 


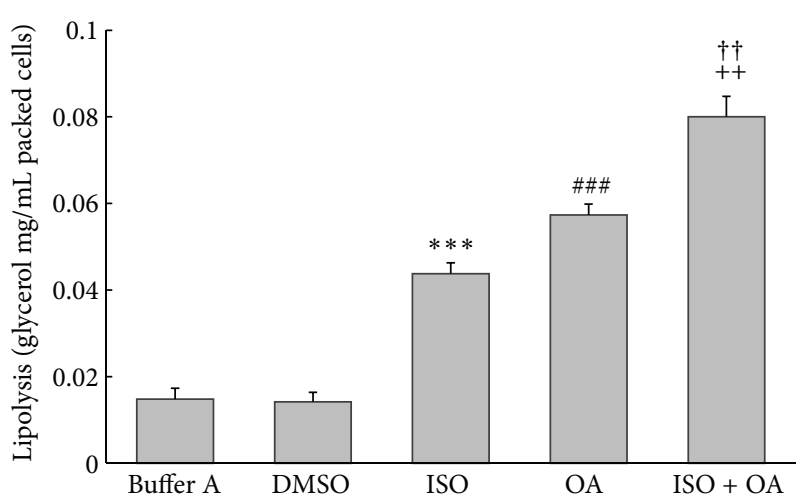

FIGURE 4: Okadaic acid enhances isoproterenol-induced glycerol release. Adipocytes were incubated for $2 \mathrm{~h}$ with isoproterenol $(10 \mu \mathrm{M})$ or okadaic acid $(1 \mu \mathrm{M})$ or both. Glycerol release was assayed (in triplicate) as an index of lipolysis and expressed as $\mathrm{mg} / \mathrm{mL}$ of packed cell volume. Data are the mean $\pm \mathrm{SE}$ of three separate experiments. ${ }^{* * *} P<0.001$ compared with buffer A group, ${ }^{\# \# \#} P<0.001$ compared with DMSO-treated group, ${ }^{++} P<$ 0.01 compared with isoproterenol-treated group, and ${ }^{\dagger \dagger} P<0.01$ compared with okadaic acid-treated group. ISO: isoproterenol; OA: okadaic acid.

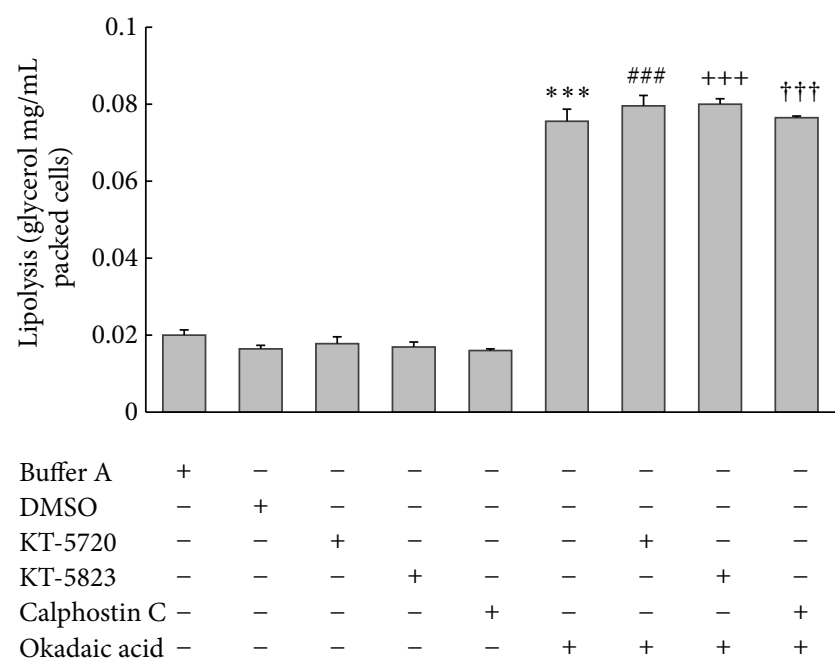

FIGURE 5: Effects of inhibitors of PKA, PKG, and PKC on okadaic acid-induced lipolysis in rat adipocytes. Cells were incubated with inhibitor alone or okadaic acid $(1 \mu \mathrm{M})$ in the absence or presence of inhibitors of PKA (KT-5720; $0.3 \mu \mathrm{M}$ ), PKG (KT-5823; $3 \mu \mathrm{M}$ ), or PKC (calphostin $\mathrm{C} ; 0.5 \mu \mathrm{M}$ ) for $2 \mathrm{~h}$ at $37^{\circ} \mathrm{C}$; media were then collected and glycerol release was measured. ${ }^{* * *} P<0.001$ compared to the DMSO-treated group, ${ }^{\# \#} P<0.001$ compared to the KT-5720treated group, ${ }^{+++} P<0.001$ compared to the KT-5823-treated group, and ${ }^{\dagger \dagger} P<0.001$ compared to the calphostin-C-treated group.

surface to the cytosol in rat adipocytes $[36,37]$. We observed here that okadaic acid treatment of rat adipocytes also leads to the detachment of perilipin A and B from the surface of lipid droplets. Thus, phosphorylation may trigger perilipin disassociation from the surface of lipid droplets. Moreover, Morimoto et al. [18] reported that okadaic acid treatment

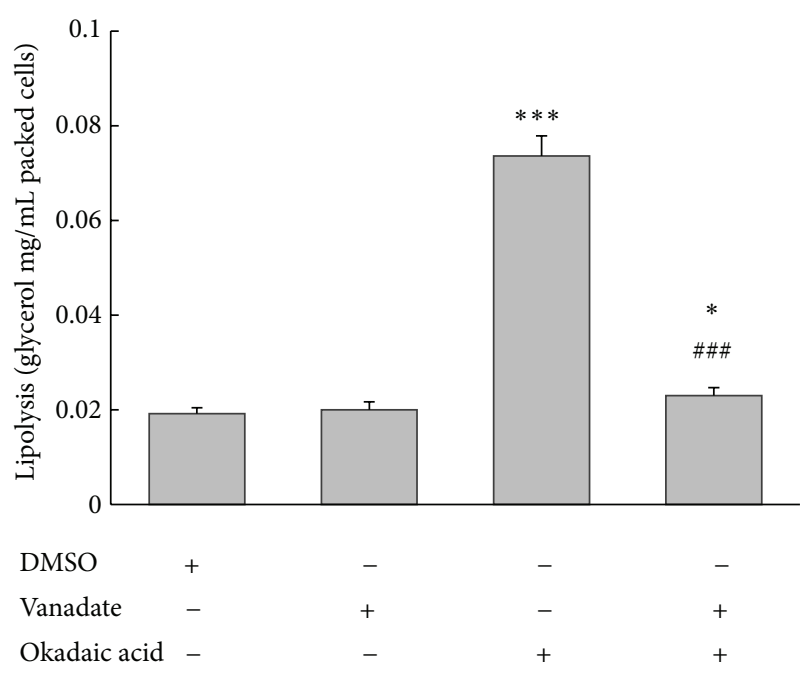

FIGURE 6: Effect of tyrosine phosphatase inhibition on okadaicacid-induced lipolysis in rat adipocytes. Cells were incubated with okadaic acid $(1 \mu \mathrm{M})$ in the absence or presence of vanadyl acetylacetonate $(300 \mu \mathrm{M})$ for $2 \mathrm{~h}$ at $37^{\circ} \mathrm{C}$. The medium was collected and glycerol release was determined. ${ }^{*} P<0.01$ and ${ }^{* * *} P<0.001$ compared to the DMSO-treated group, ${ }^{\# \# \# ~} P<0.001$ compared to the okadaic-acid-treated group. Vanadate: vanadyl acetylacetonate.

does not increase the catalytic activity of HSL but induces the translocation of HSL to the lipid droplets. Phosphorylated HSL translocates from the cytosol to the surface of lipid droplets [37, 38], and phosphorylated perilipins might detach from the surface of droplets to expose the triacylglycerol stored in lipid droplets and then facilitate lipid hydrolysis by HSL [20, 22].

On the other hand, we found that when adipocytes were incubated with okadaic acid or isoproterenol, at different incubation periods ( $0-30 \mathrm{~min})$, the expression levels of betaactin in lipid droplets remain unchanged. The cytoskeleton proteins associated with lipid droplets seem to be resistant to drug treatment. For example, formation of vimentin intermediate filamentous cages enclosed and protected the nascent lipid droplets of 3T3-L1 adipocytes from disruption of colchicine treatment [39]. Hence, we suggested that the lipiddroplet-associated beta-actin might be a stable structural protein on the surface of intracellular lipid droplet.

In this study, isoproterenol-induced lipolysis was enhanced by okadaic acid treatment, which agrees with the previous results [16]. Isoproterenol-stimulated lipolysis, but not okadaic-acid-induced lipolysis, was antagonized by insulin in a previous study [35], and we found that okadaicacid-induced lipolysis was not inhibited by a PKA blocker (KT-5720). These findings suggest that okadaic acid and isoproterenol stimulate lipolysis through distinct signaling pathways.

PKA is involved in catecholamine- or isoproterenolinduced lipolysis, and PKG is responsible for lipolysis stimulated by atrial natriuretic peptide [4]. Because the specific inhibitors of PKA (KT-5720) and PKG (KT-5823) did not 
abolish or attenuate okadaic-acid-induced glycerol release in our study, we suggest that neither PKA nor PKG is involved in okadaic-acid-induced lipolysis in rat adipocytes. Okadaic acid has been reported to inhibit PP2A and activate protein kinase $B(\mathrm{PKB})[40]$ and then promote the translocation of glucose transporter 4 (GLUT4) from cytosol to cell membrane and increase glucose uptake in adipocytes [41]. In the case of okadaic acid treatment, glucose uptake and GLUT4 translocation in rat adipocytes and 3T3-L1 preadipocytes might be mediated through the activation of PKC-zeta and/or PKC-lambda [42]. These reports suggest that PKB and PKC are responsible for okadaic-acid-induced glucose uptake. Calphostin C, a specific PKC inhibitor, did not block okadaicacid-induced lipolysis in this study, indicating that PKC is not directly involved in okadaic-acid-induced lipolysis. Additional experiments are required to determine whether PKB signaling participates in okadaic acid-induced lipolysis.

In rat adipocytes, vanadate mimics the antidiabetic effects of insulin and also inhibits catecholamine-induced lipolysis [43]. However, the antilipolytic action of vanadate is distinct mechanistically from that of insulin because wortmannin, a phosphoinositol 3-kinase (PI3K) inhibitor that blocked the antilipolytic effect of insulin, failed to block vanadatemediated antilipolysis [35], indicating that PI3K did not participate in antilipolytic signaling initiated by vanadate. Vanadate has been shown to inhibit protein tyrosine phosphatases (PTPases) [44] and activate membranous nonreceptor protein tyrosine kinases (membPTKs) and thereby stimulate protein tyrosine phosphorylation in rat adipocytes [45]. It is reported that several organic vanadyl compounds had anti-lipolytic activity. The vanadyl acetylacetonate had the most powerful potency, and it correlated better with the inhibition of adipose membrane-PTPase in cell-free experiments [35]. Moreover, the PTK blocker staurosporine can reverse the antilipolytic effect of vanadate [45]. These findings suggest that the inhibitory effect of vanadyl acetylacetonate on okadaic-acid-induced lipolysis might be mediated by PTPases or membPTKs in rat adipocytes. However, the effects of PTPases and membPTKs on HSL and perilipins warrant further investigation.

In conclusion, we found that one treatment with okadaic acid resulted in detachment of perilipin A and B from lipid droplets. The molecular weight of perilipin A shifted from $62 \mathrm{kD}$ to $65 \mathrm{kD}$ after incubating cells with okadaic acid for $5 \mathrm{~min}$, and after perilipins detached from lipid droplets, glycerol release increased. Although okadaic acid and isoproterenol might produce their lipolytic effects through distinct mechanisms in rat adipocytes, both drugs induced the detachment of perilipins from lipid droplets and stimulated glycerol release. This study suggested that okadaic acid may regulate lipid metabolism by mediating the activity of protein phosphatases and the translocation of perilipins.

\section{Conflict of Interests}

The authors declare that there is no conflict of interests regarding the publication of this paper.

\section{Authors' Contribution}

Dr. Nen-Chung Chang and Dr. Aming Chor-Ming Lin contributed equally to this work.

\section{Acknowledgments}

This study was supported by research Grants from Taipei Medical University Hospital (100-TMU-TMUH-03) and Shin Kong Wu Ho-Su Memorial Hospital (SKH-TMU-93-33).

\section{References}

[1] D. W. Haslam and W. P. T. James, “Obesity”, The Lancet, vol. 366, no. 9492, pp. 1197-1209, 2005.

[2] P. Bjorntorp, "Abdominal fat distribution and disease: an overview of epidemiological data," Annals of Medicine, vol. 24, no. 1, pp. 15-18, 1992.

[3] G. Schmitz, C. Aslanidis, and K. J. Lackner, "Recent advances in molecular genetics of cardiovascular disorders implications for atherosclerosis and diseases of cellular lipid metabolism," Pathology and Oncology Research, vol. 4, no. 2, pp. 152-160, 1998.

[4] M. Lafontan and D. Langin, "Lipolysis and lipid mobilization in human adipose tissue," Progress in Lipid Research, vol. 48, no. 5, pp. 275-297, 2009.

[5] C. C. Fan and R. J. Ho, "Response of white adipocyte of mouse and rabbit to catecholamines and ACTH. I. Correlation of cyclic AMP levels and initial rates of lipolysis," Molecular and Cellular Biochemistry, vol. 34, no. 1, pp. 35-41, 1981.

[6] P. Stralfors, P. Bjorgell, and P. Belfrage, "Hormonal regulation of hormone-sensitive lipase in intact adipocytes: identification of phosphorylated sites and effects on the phosphorylation by lipolytic hormones and insulin," Proceedings of the National Academy of Sciences of the United States of America, vol. 81, no. 11 I, pp. 3317-3321, 1984.

[7] A. S. Greenberg, J. J. Egan, S. A. Wek, N. B. Garty, E. J. Blanchette-Mackie, and C. Londos, "Perilipin, a major hormonally regulated adipocyte-specific phosphoprotein associated with the periphery of lipid storage droplets," The Journal of Biological Chemistry, vol. 266, no. 17, pp. 11341-11346, 1991.

[8] C. Londos, C. Sztalryd, J. T. Tansey, and A. R. Kimmel, "Role of PAT proteins in lipid metabolism," Biochimie, vol. 87, no. 1, pp. 45-49, 2005.

[9] A. Takai, C. Bialojan, M. Troschka, and J. Caspar Rüegg, "Smooth muscle myosin phosphatase inhibition and force enhancement by black sponge toxin," FEBS Letters, vol. 217, no. 1, pp. 81-84, 1987.

[10] C. Bialojan and A. Takai, "Inhibitory effect of a marine-sponge toxin, okadaic acid, on protein phosphatases. Specificity and kinetics," Biochemical Journal, vol. 256, no. 1, pp. 283-290, 1988.

[11] M. Suganuma, H. Fujiki, H. Suguri et al., "Okadaic acid: an additional non-phorbol-12-tetradecanoate-13-acetate-type tumor promoter," Proceedings of the National Academy of Sciences of the United States of America, vol. 85, no. 6, pp. 17681771, 1988.

[12] S. J. Mistry, H.-C. Li, and G. F. Atweh, "Role for protein phosphatases in the cell-cycle-regulated phosphorylation of stathmin," Biochemical Journal, vol. 334, no. 1, pp. 23-29, 1998.

[13] R. Nuydens, M. De Jong, G. Van Den Kieboom et al., "Okadaic acid-induced apoptosis in neuronal cells: evidence for an 
abortive mitotic attempt," Journal of Neurochemistry, vol. 70, no. 3, pp. 1124-1133, 1998.

[14] K. Pahan, F. G. Sheikh, A. M. S. Namboodiri, and I. Singh, "Inhibitors of protein phosphatase 1 and $2 \mathrm{~A}$ differentially regulate the expression of inducible nitric-oxide synthase in rat astrocytes and macrophages," The Journal of Biological Chemistry, vol. 273, no. 20, pp. 12219-12226, 1998.

[15] R. A. Easom, J. L. Tarpley, N. R. Filler, and H. Bhatt, "Dephosphorylation and deactivation of $\mathrm{Ca}^{2+} /$ calmodulin-dependent protein kinase II in betaTC3-cells is mediated by $\mathrm{Mg}^{2+}$ - and okadaic-acid-sensitive protein phosphatases," The Biochemical journal, vol. 329, no. 2, pp. 283-288, 1998.

[16] T. A. J. Haystead, A. T. R. Sim, D. Carling et al., "Effects of the tumour promoter okadaic acid on intracellular protein phosphorylation and metabolism," Nature, vol.337, no. 6202, pp. 78-81, 1989.

[17] P. Cohen, C. F. B. Holmes, and Y. Tsukitani, "Okadaic acid: a new probe for the study of cellular regulation," Trends in Biochemical Sciences, vol. 15, no. 3, pp. 98-102, 1990.

[18] C. Morimoto, A. Kiyama, K. Kameda, H. Ninomiya, T. Tsujita, and H. Okuda, "Mechanism of the stimulatory action of okadaic acid on lipolysis in rat fat cells," Journal of Lipid Research, vol. 41, no. 2, pp. 199-204, 2000.

[19] E. J. Blanchette-Mackie, N. K. Dwyer, T. Barber et al., "Perilipin is located on the surface layer of intracellular lipid droplets in adipocytes," Journal of Lipid Research, vol. 36, no. 6, pp. 12111226, 1995.

[20] P. E. Bickel, J. T. Tansey, and M. A. Welte, "PAT proteins, an ancient family of lipid droplet proteins that regulate cellular lipid stores," Biochimica et Biophysica Acta, vol. 1791, no. 6, pp. 419-440, 2009.

[21] A. S. Greenberg, J. J. Egan, S. A. Wek, M. C. Moos Jr., C. Londos, and A. R. Kimmel, "Isolation of cDNAs for perilipins A and B: sequence and expression of lipid droplet-associated proteins of adipocytes," Proceedings of the National Academy of Sciences of the United States of America, vol. 90, no. 24, pp. 12035-12039, 1993.

[22] C. Sztalryd, G. Xu, H. Dorward et al., "Perilipin A is essential for the translocation of hormone-sensitive lipase during lipolytic activation," Journal of Cell Biology, vol. 161, no. 6, pp. 1093-1103, 2003.

[23] J. He, H. Jiang, J. T. Tansey, C. Tang, S. Pu, and G. Xu, "Calyculin and okadaic acid promote perilipin phosphorylation and increase lipolysis in primary rat adipocytes," Biochimica et Biophysica Acta, vol. 1761, no. 2, pp. 247-255, 2006.

[24] T.-H. Fong, C.-H. Wu, E.-W. Liao et al., "Association of globular $\beta$-actin with intracellular lipid droplets in rat adrenocortical cells and adipocytes," Biochemical and Biophysical Research Communications, vol. 289, no. 5, pp. 1168-1174, 2001.

[25] H. Yuasa, K. Yoshida, H. Iwata, H. Nakanishi, M. Suganuma, and M. Tatematsu, "Increase of labeling indices in gastrointestinal mucosae of mice and rats by compounds of the okadaic acid type," Journal of Cancer Research and Clinical Oncology, vol. 120, no. 4, pp. 208-212, 1994.

[26] G. Berven, F. Sætre, K. Halvorsen, and P. O. Seglen, "Effects of the diarrhetic shellfish toxin, okadaic acid, on cytoskeletal elements, viability and functionality of rat liver and intestinal cells," Toxicon, vol. 39, no. 2-3, pp. 349-362, 2000.

[27] H. Fujiki, M. Suganuma, H. Suguri et al., "Diarrhetic shellfish toxin, dinophysistoxin-1, is a potent tumor promotor on mouse skin," Japanese Journal of Cancer Research, vol. 79, no. 10, pp. 1089-1093, 1988.
[28] E. E. Creppy, A. Traoré, I. Baudrimont, M. Cascante, and M.R. Carratú, "Recent advances in the study of epigenetic effects induced by the phycotoxin okadaic acid," Toxicology, vol. 181182, pp. 433-439, 2002.

[29] S. Cordier, C. Monfort, L. Miossec, S. Richardson, and C. Belin, "Ecological analysis of digestive cancer mortality related to contamination by diarrhetic shellfish poisoning toxins along the coasts of France," Environmental Research, vol. 84, no. 2, pp. 145150, 2000.

[30] M. Rodbell, "Metabolism of isolated fat cells," The Journal of Biological Chemistry, vol. 239, no. 2, pp. 375-380, 1964.

[31] H. Okuda, C. Morimoto, and T. Tsujita, "Role of endogenous lipid droplets in lipolysis in rat adipocytes," Journal of Lipid Research, vol. 35, no. 1, pp. 36-44, 1994.

[32] S. L. Wood, N. Emmison, A. C. Borthwick, and S. J. Yeaman, "The protein phosphatases responsible for dephosphorylation of hormone-sensitive lipase in isolated rat adipocytes," Biochemical Journal, vol. 295, no. 2, pp. 531-535, 1993.

[33] H. Olsson and P. Belfrage, "The regulatory and basal phosphorylation sites of hormone-sensitive lipase are dephosphorylated by protein phosphatase-1, 2A and 2C but not by protein phosphatase-2B," European Journal of Biochemistry, vol. 168, no. 2, pp. 399-405, 1987.

[34] G. M. Clifford, D. K. T. McCormick, C. Londos, R. G. Vernon, and S. J. Yeaman, "Dephosphorylation of perilipin by protein phosphatases present in rat adipocytes," FEBS Letters, vol. 435, no. 1, pp. 125-129, 1998.

[35] J. Li, G. Elberg, N. Sekar, Z. B. He, and Y. Shechter, "Antilipolytic actions of vanadate and insulin in rat adipocytes mediated by distinctly different mechanisms," Endocrinology, vol. 138, no. 6, pp. 2274-2279, 1997.

[36] G. M. Clifford, D. K. T. McCormick, R. G. Vernon, and S. J. Yeaman, "Translocation of perilipin and hormone-sensitive lipase in response to lipolytic hormones," Biochemical Society Transactions, vol. 25, no. 4, p. S672, 1997.

[37] G. M. Clifford, C. Londos, F. B. Kraemer, R. G. Vernon, and S. J. Yeaman, "Translocation of hormone-sensitive lipase and perilipin upon lipolytic stimulation of rat adipocytes," The Journal of Biological Chemistry, vol. 275, no. 7, pp. 5011-5015, 2000.

[38] J. J. Egan, A. S. Greenberg, M.-K. Chang, S. A. Wek, M. C. Moos Jr., and C. Londos, "Mechanism of hormone-stimulated lipolysis in adipocytes: translocation of hormone-sensitive lipase to the lipid storage droplet," Proceedings of the National Academy of Sciences of the United States of America, vol. 89, no. 18, pp. 8537-8541, 1992.

[39] W. W. Franke, M. Hergt, and C. Grund, "Rearrangement of the vimentin cytoskeleton during adipose conversion: formation of an intermediate filament cage around lipid globules," Cell, vol. 49, no. 1, pp. 131-141, 1987.

[40] S. Resjö, O. Göransson, L. Härndahl, S. Zolnierowicz, V. Manganiello, and E. Degerman, "Protein phosphatase 2A is the main phosphatase involved in the regulation of protein kinase $\mathrm{B}$ in rat adipocytes," Cellular Signalling, vol. 14, no. 3, pp. 231-238, 2002.

[41] J.-F. Tanti, S. Grillo, T. Gremeaux, P. J. Coffer, E. Van Obberghen, and Y. L. Marchand- Brustel, "Potential role of protein kinase B in glucose transporter 4 translocation in adipocytes," Endocrinology, vol. 138, no. 5, pp. 2005-2010, 1997.

[42] M. L. Standaert, G. Bandyopadhyay, M. P. Sajan, L. Cong, M. J. Quon, and R. V. Farese, "Okadaic acid activates atypical 
protein kinase $\mathrm{C}(\zeta / \lambda)$ in rat and 3T3/L1 adipocytes: an apparent requirement for activation of GLUT4 translocation and glucose transport," The Journal of Biological Chemistry, vol. 274, no. 20, pp. 14074-14078, 1999.

[43] Y. Shechter, "Insulin-mimetic effects of vanadate. Possible implications for future treatment of diabetes," Diabetes, vol. 39, no. 1, pp. 1-5, 1990.

[44] B. Mukherjee, B. Patra, S. Mahapatra, P. Banerjee, A. Tiwari, and M. Chatterjee, "Vanadium-an element of atypical biological significance," Toxicology Letters, vol. 150, no. 2, pp. 135-143, 2004.

[45] G. Elberg, Z. He, J. Li, N. Sekar, and Y. Shechter, "Vanadate activates membranous nonreceptor protein tyrosine kinase in rat adipocytes," Diabetes, vol. 46, no. 11, pp. 1684-1690, 1997. 


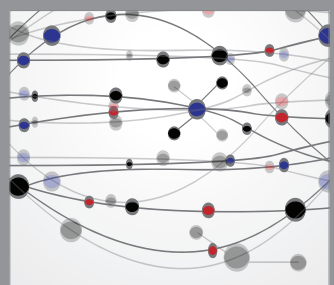

The Scientific World Journal
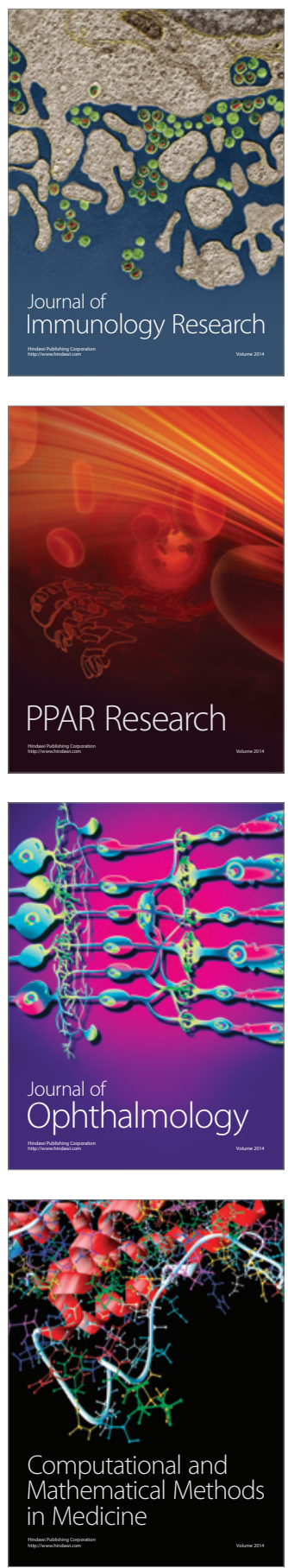

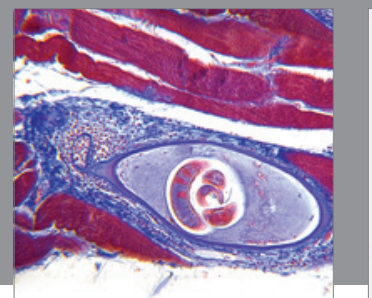

Gastroenterology

Research and Practice
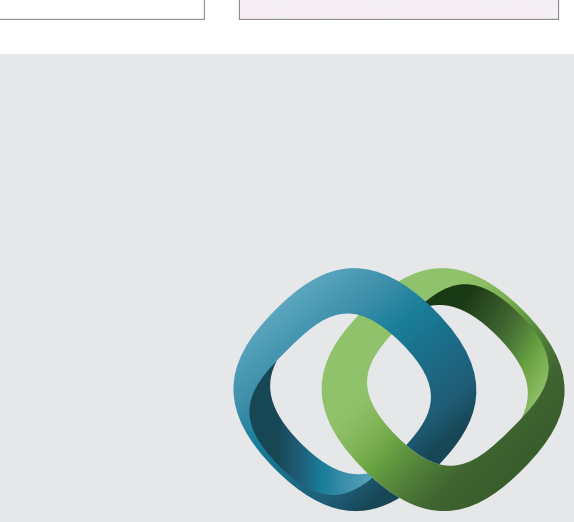

\section{Hindawi}

Submit your manuscripts at

http://www.hindawi.com
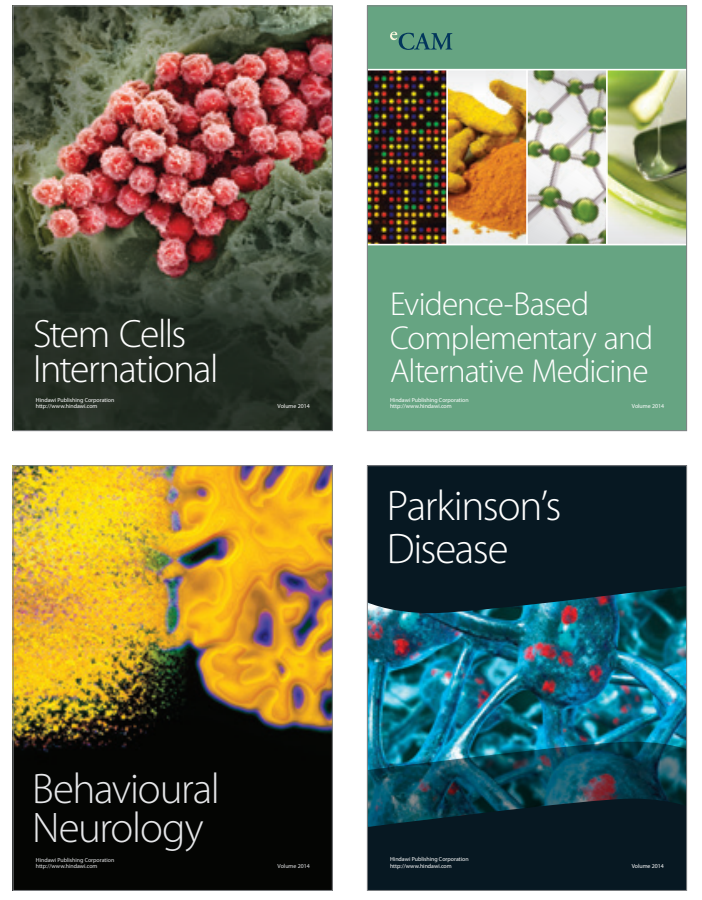
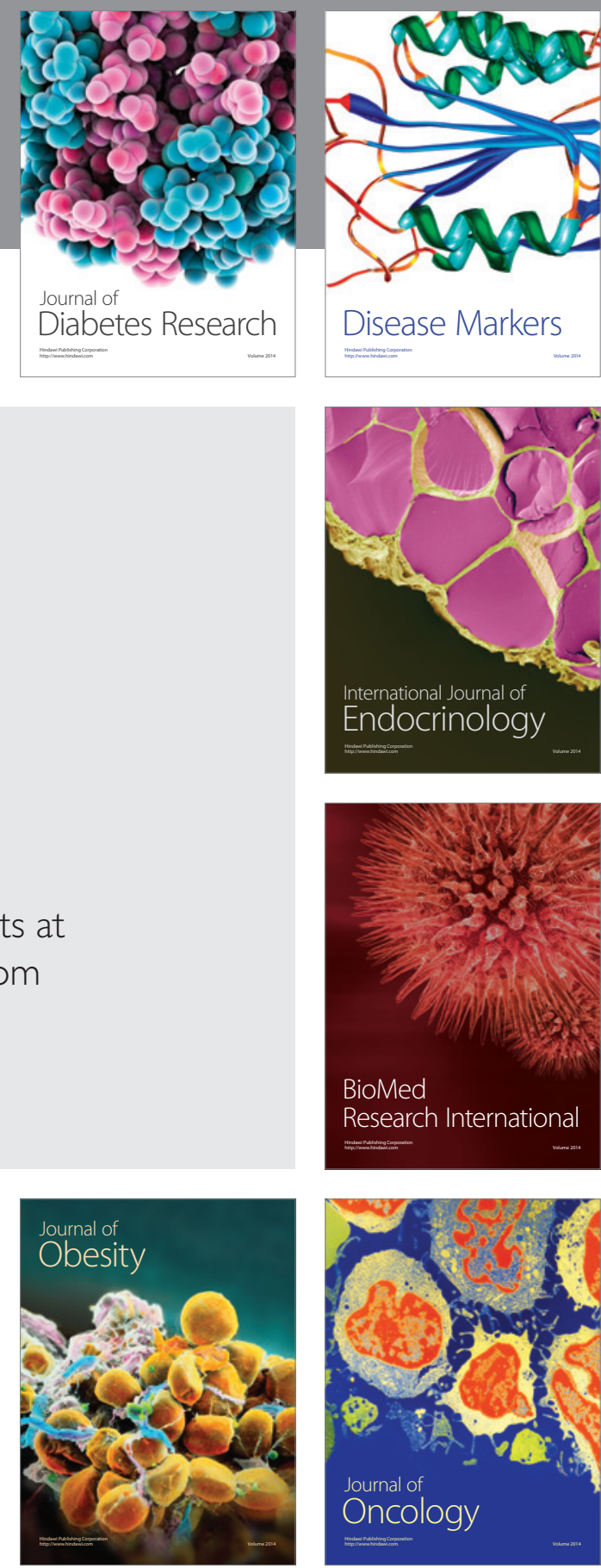

Disease Markers
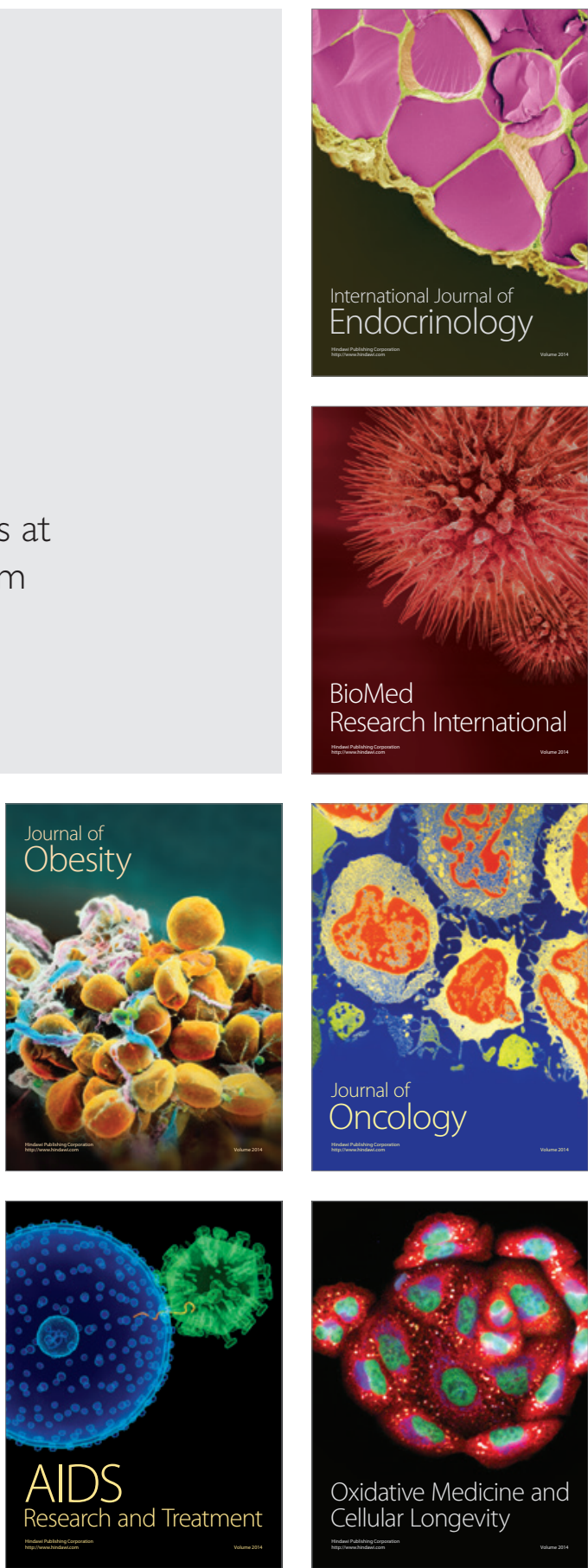